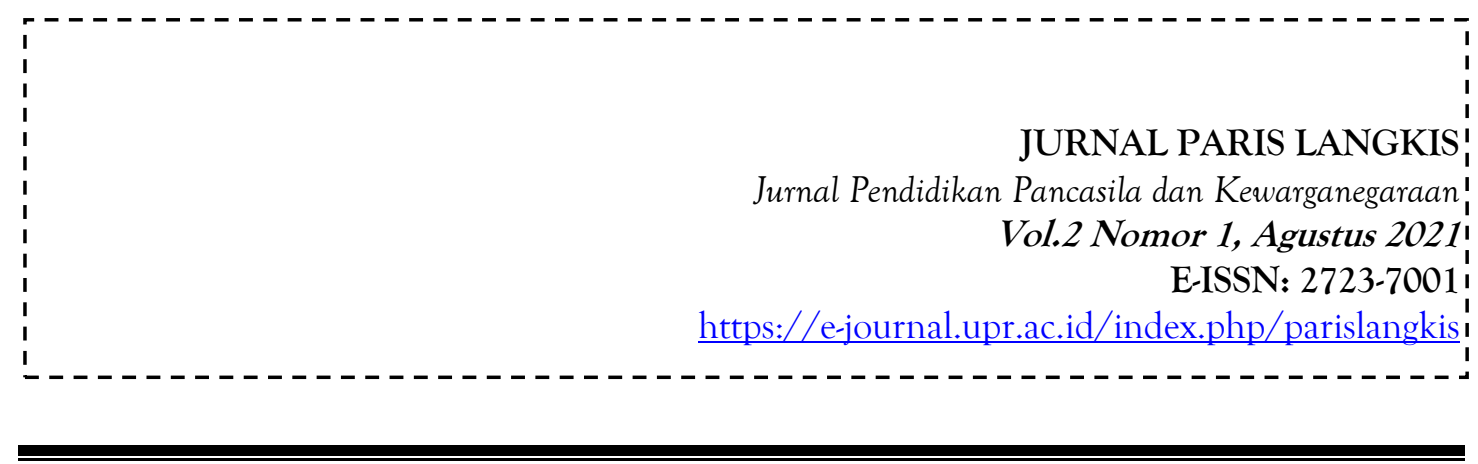

\title{
PELAKSANAAN TUGAS DAN WEWENANG BADAN KEHORMATAN DPRD KABUPATEN KUPANG DALAM MENJAGA KEHORMATAN ANGGOTA DPRD
}

\author{
Nilson F. Ndolu
}

Mahasiswa Fakultas Hukum Pasca Sarjana UNDANA Kupang/ Tenaga Ahli Fraksi Partai NasDem DPRD Kabupaten Kupang

E-mail:ndolu.nelson@yahoo.com

\begin{abstract}
Abstrak
Tulisan ini mengenai pelaksanaan tugas dan wewenang Badan Kehormatan Dewan Perwakilan Rakyat Daerah Kabupaten Kupang dalam menjaga kehormatan anggota Dewan Perwakilan Rakyat Daerah. Rumusan masalah dalam penelitian ini ialah; Bagaimanakah kendala dalam penerapan Putusan Badan Kehormatan Dewan Perwakilan Rakyat Daerahterhadap anggota yang melanggar kode etik,danApakah kode etik Dewan Perwakilan Rakyat Daerah telah memenuhi dan menjamin kewibawaan dan kehormatan anggota Dewan Perwakilan Rakyat Daerah. Penelitian ini bersifat yuridis empirik. Hasil penelitian menunjukan bahwa: pertama, Badan Kehormatan dalam penegakan kode etik belum maksimal dan belum sesuai dengan apa yang diharapkan.Kedua, Lemahnya Tata Tertib dan kode etik DPRD menyababkan Badan Kehormatan tidak banyak berbuat.

Kata Kunci: Badan Kehormatan DPRD, Tugas dan wewenang, Kode etik

\section{Abstract}

This paper on the implementation of the duties and authority of the Honorary Board of Kupang Regency Regional Representatives in maintaining the honor of the House of Representatives. The problem in this research is; How obstacle in the implementation of the Decision of the Honorary Council of Representatives against members who violate the code of ethics and code of conduct Does the Regional Representatives Council has met and ensure the integrity and honor of the members of the Regional Representatives Council. The research is juridical empirical method using sociological approach. The results showed that: first, the Honorary Board of the enforcement of the code of conduct is not maximized
\end{abstract}

\section{Paris Langkis}

Vol.2 Nomor 1, Agustus 2021 
and not in accordance with what is expected. Second, the weakness of the Standing Orders of Parliament and a code of conduct so that the honor was not much to,do Keywords: Honorary Board of the Parliament, tasks and powers, code of ethics

\section{A. PENDAHULUAN}

Pasca tumbangnya Orde Baru dan berganti baju Orde Reformasi aneka problem terus membelit bangsa ini seolah tanpa jeda, dari sosial, ekonomi, politik dan hukum. Sebagai sebuah bangsa berdasar hukum (rechstaat) yang meyakini hukum sebagai penopang utama kokoh berdirinya bangunan "rumah bersama" bernama Indonesia. Komponen utama tegaknya hukum adalah hadirnya peraturan perundang-undangan yang memadai, bukan saja prosedur teknis pembuatannya (legal drafting) ("Strategi Politik Hukum Meningkatkan Kualitas Kinerja DPR RI dalam roduktivitas Legislasi Nasional”, Jurnal Cita Hukum, , Edisi September 2016, ) yang demokratis, akan tetapi juga substansi materinya yang bermutu dan mampu dijadikan rujukan dan panduan berbangsa tanpa bertentangan dengan kehendak dan keinginan publik.

Undang-Undang Dasar Negara Republik Indonesia Tahun 1945mengamanatkan bahwa Negara Kesatuan Republik Indonesia adalah Negara yang berkedaulatan rakyat yang dalam pelaksanaannya menganut prinsip kerakyatan yang dipimpin oleh hikmat kebijaksanaan dalam permusyawaratan/perwakilan. untuk mengembangkan kehidupan demokrasi dalam penyelenggaraan pemerintahan daerah, perlu juga diwujudkan lembaga perwakilan rakyat daerah (DPRD) sebagai penyelenggara pemerintahan daerah bersama dengan pemerintah daerah sehingga mampu mengatur dan mengurus urusan pemerintahan dan kepentingan masyarakat setempat berdasarkan aspirasi masyarakat dalam kerangka Negara Kesatuan Republik Indonesia ( "Peranan Sekretariat DPRD Dalam Mendukung Fungsi DPRD (studi di Sekretariat DPRD kota Tomohon)”, , Edisi September 2013).

Fenomena ketatanegaraan ini sesungguhnya mengajarkan bahwa pelaksanaan fungsi DPR sangat strategis dalam menentukan bentuk bulat-lonjongnya sebuah produk. Kualitas produk legislasi sudah barang pasti menjadi tanggungjawab DPR. Karena sesungguhnya dalam konteks pelembagaan demokrasi melalui produk fungsi DPR sangat berpengaruh dalam menuntaskan arah dari konsolidasi demokrasi (Hendri \& Firdaus, 2021). Urgensitas pelaksanaan fungsi itu dapat dimulai dengan mengukur tingkat kualitas. Ia menjadi kunci keberhasilan konsolidasi demokrasi.

Dewan Perwakilan Rakyat Daerah (DPRD) adalah merupakan lembaga legislatif yang para anggotanya terpilih melalui mekanisme pemilihan umum, sebagai sebuah institusi, keberadaan sangat penting dan strategis dalam melaksanakan perannya guna mewujudkan pemerintahan yang baik dan bersih (good and clean governance) dalam menjalankan fungsinya perlu senantiasa mengedepankan komitmen moral dan profesionalitas. Komitmen tersebut menjadi sangat penting sebagai upaya untuk mewujudkan DPRD yang produktif, terpecaya 
dan beribawa. Anggota DPRD perlu menyadari bahwa tugas dan tanggung jawabnya sangat berat, bukan hanya dalam konteks horizontal terhadap konstituen, melainkan juga secara vertikal kepada Tuhan Yang Maha Esa sebagaimana yang telah termaktub dalam sumpah jabatan, sehingga dalam menjalankan tugasnya senantiasa mengacu pada peraturan perundang-undangan yang ada (Arbi Sanit, 1985). Untuk itu, guna melaksanakan Pemerintahan Daerah yang demokratis perlu dilakukan optimalisasi tugas dan fungsi Dewan Perwakilan Rakyat Daerah.

Badan Kehormatan (BK) sebagai salah satu alat kelengkapan dewan mempunyai peranan yang sangat penting berhubungan dengan pelaksanaan tugas, fungsi dan kewenangan DPRD, karenalembaga ini menyangkut masalah kehormatan dan martabat para wakil rakyat di DPRD. Maraknya fenomena anggota dewan yang telah terpilih menduduki kursi legislative bekerja seenaknya tanpa ada orang lain yang memperdulikan ataupun mengawasinya seperti jarang hadir dalam kegiatan dinas, sidang ataupun rapat, padahal masalah yang dibahas berkaitan erat dengan kepentingan pemilihnya ataupun rakyat. Dan ironisnya, kebanyakan dari anggota dewan hanya masuk untuk mengisi absen dan kemudian pergi lagi untuk melakukan kegiatan rekreasi ataupun bisnis di tempat lain. Bahkan DPRD dikritik oleh masyarakat karena sering jalan-jalan keluar daerah bahkan ke luar negeri sementara masih banyak masalah-masalah dalam daerah yang belum teratasi ( "Peran badan kehormatan terhadap pelaksanaan kode etik dalam Meningkatkan pertanggungjawaban DPRD”, Maret 2016,).

Berbagai kelompok masyarakat yang kritis terhadap eksekutif memberikan rapor merah bagi kinerja Badan Kehormatan. BK dinilai belum optimal dalam mengarahkan anggota legislatif bekerja sesuai dengan kode etik yang berlaku. Tidak hanya itu, inisiatif dan respons BK DPRD terhadap pelanggaran kode etik yang dilakukan anggota DPRD juga dianggap masih sangat rendah ("Suap dalam Proses Legislasi, Penelusuran Awal", Oktober 2005. ). Kondisi terakhir setiap partai yang ada di BK diduga seperti telah tersandera. Mereka sepertinya saling menutupi dan saling bersandiwara ketika ada berbagai kasus-kasus yang melilit dan menghimpit yang terjadi pada partainya masing-masing ("Tugas dan Fungsi Badan Kehormatan DPR”,, Juni 2012 ). Mereka sudah saling melindungi bila terjadi keburukan pada masing-masing. Karenanya, keberadaan BK sudah tidak lagi efektif,- Harus ada kekutan yang dapat mencairkan kondisi seperti ini, tak terkecuali, Kode Etik DPRD pun membutuhkan kritik agar terdapat acuan moralitas yang berjalan sesuai perkembangan ketatanegaraan dan kehidupan politik yang lebih matang ( Peran BK-DPRD dalam Penegakan Etika”,, Mei 2015 hlm 2).

Badan Kehormatan bekerja dan kode etik adalah pedoman perilakunya. Dalam pelaksanaannya, BK memiliki dua sanksi yang sangat penting, yaitu sanksi moral dan sanksi hukum. Sedangkan sanksi dalam tata tertibnya terdiri dari beberapa sanksi, yaitu teguran lisan, teguran tertulis, pemindahan keanggotaan pada alat kelengkapan DPR-RI/DPRD, pemberhentian dari pimpinan DPR-RI/DPRD 
atau pimpinan alat kelengkapan DPR-RI, pemberhentian sementara; atau pemberhentian sebagai Anggota DPR-RI. Sebagai pejabat negara, DPR harus bersifat negarawan yang bijak dan mempunyai moral yang luhur, patuh terhadap hukum dalam menjalankan tugas, karena pada sejatinya ia adalah pemimpin dalam lembaga perwakilan yang menjadi contoh masyarakat ( Praktik Pengawasan Etika Dewan Perwakilan Rakyat Republik Indonesia”, Edisi Juni 2014, ).

Badan Kehormatan DPRD Kabupaten Kupang Provinsi NTT periode 2014 2019 dalam menjalankan tugas dan wewenangnya saat ini dipertanyakan, terutama setelah beberapa anggota DPRD Kabupaten Kupang terlibat dalam berbagai pelanggaran kode etik. Hal ini sudah bukan menjadi rahasia umum lagi dimata masyaraka. Media online kupang media.com selasa, 15 November 2016 merilis berita dengan judul Waduh, Anggota DPRD Kabupaten Kupang menipu janda Ratusan Juta Rupiah ("Waduh anggota DPRD-kabupaten kupang tipu janda ratusan juta rupiah" tersedia di website http://www.kupangmedia.com/, 13 November 2016 ), Harian Umum Pos Kupang 7 oktober 2016 merilis berita Pesta Bir di Gedung DPRD Kabupaten Kupang, Anggota Dewan Meradang (Akoit, 2017), Surat Kabar Timor Express 13 desember 2016 dengan judul berita Anggota DPRD Kabupaten Kupang, sekamar dengan istri orang, (Boi, di akses pada 13 Februari 2017 ) dan dugaan pelanggaran etik lainnya. Akibatnya, terjadi krisis moral maupun integritas yang kian banyak dalam badan DPRD tersebut. Sementara disisi lain Badan Kehormatan diharapkan berperan tidak hanya sekadar menjadi penjaga moral dan integritas anggota DPRD kabupaten Kupang, melainkan juga menjadi pengawal mekanisme internal untuk menegakan kode etik DPRD kabupaten Kupang. Dalam kaitan tersebut, maka makalah ini hendak membahas mengenai Pelaksanaan Tugas dan Wewenang Badan Kehormatan DPRD Kabupaten Kupang Dalam Menjaga Kehormatan Anggota DPRD.

Berdasarkan uraian latar belakang masalah tersebut di atas, maka ada dua permasalahan yang dibahas dalam makalah ini. Pertama,Bagaimana penerapan pengambilan Putusan Badan Kehormatan DPR/DPRD yang melanggar kode etik Kedua,Bagaimana Pengaruh/Dampak Putusan Badan Kehormatan terhadap keanggotaan DPR/DPRD?

\section{B. METODE PENELITIAN}

Jenis penelitian dapat dikelompokkan menurut tujuan, pendekatan, tingkat eksplanasi, dan jenis Data. Sesuai dengan tujuan penelitian ini ialah Untuk mengkaji dan mendiskripsikan pelaksanaan tugas dan wewenang Badan Kehormatan Dewan Perwakilan Rakyat Daerah dalam menjaga kehormatan anggota DPRD Kabupaten Kupang berdasarkan kode etik DPRD dan Untuk menemukan dan mengkaji serta mendeskripsikan faktor-faktor yang mempengaruhi Badan Kehormatan DPRD berdasarkan kode etik DPRD, maka

metode yang cocok digunakan dalam penelitian ini adalah metode kualitatif 
(Peranan Sekretariat DPRD Dalam Mendukung Fungsi DPRD (studi di Sekretariat DPRD kota Tomohon)).

Cara pengukuran variable penelitian biasanya dirumuskan dalam apa yang disebut definisi konsepsional dan definisi operasional. Definisi konsepsional adalah istilah atau definisi yang digunakan untuk menggambarkan secara abstrak : kejadian, keadaan, kelompok atau individu yang menjadi pusat perhatian ilmu sosial.

Jenis data yang dikumpulkan untuk dianalisis dalam penelitian ini ialah data primer atau data yang bersumber langsung dari informan/responden yang ditentukan. Sementara itu data sekunder yang dikumpulkan hanya berfungsi sebagai pelengkap data primer. Salah satu sifat penelitian kualitatif ialah tidak mementingkan jumlah sumber data/informan, tetapi yang lebih dipentingkan ialah content, relevansi, dan sumber yang benar-benar dapat memberikan informasi, baik mengenai orang, peristiwa atau hal ("Tugas dan Wewenang Badan Anggaran DPRD Kota Bekasi Dalam Penyusunan Anggaran Pendapatan dan Belanja Daerah (APBD)”, , Edisi 2012).

Teknik pengumpulan data yang digunakan ialah wawancara dan dilengkapi dengan teknik observasi dan dokumentasi. Metode pengumpulan data tersebut digunakan dengan pertimbangan : (1) menyesuaikan metode kualitatif lebih mudah apabila berhadapan dengan kenyataan jamak; (2) metode ini bertujuan menyajikan secara langsung hakekat hubungan antara peneliti dan responden, dan (3) metode ini lebih peka dan lebih dapat menyesuaikan diri dengan banyak penajaman pengaruh bersama terhadap pola-pola nilai yang dihadapi (1) Wawancara ; digunakan untuk mengumpulkan data primer dari informan yang terpilih. Dalam melakukan wawancara ini digunakan pedoman wawancara yang telah dipersiapkan terlebih dahulu (Tugas dan Wewenang DPRD dalam Pelaksanaan Pengawasan APBD di Kabupaten Bekasi , 2013, ).

Adapun langkahlangkah analisis data yang dimaksudkan yaitu terdiri dari : pengumpulan data, reduksi data, penyajian data, dan penarikan kesimpulan (Soejono Soekanto, 2007).

\section{PEMBAHASAN}

Berdasarkan hasil penelitian yang dilakukan oleh penulis maka terkait dengan pelanggaran-pelanggaran yang telah di uraikan pada latar belakang masalah, diakui oleh Badan Kehormatan (BK) bahwa tidak semua Pelanggaran yang disebutkan itu diproses. Yang ditindak lanjuti oleh BK hanya terkait dengan masalah indisipliner yaitu BK sempat menegur salah satu anggota DPRD yang tidak mengunakan pakian seragam/sipil resmi pada saat menghadiri Pembukaan Rapat Paripurna hal ini tidak sesuai dengan ketentuan yang berlaku dalam dalam Tata Tertib Pasal 113 ayat 2 (dalam hal menghadiri Rapat Paripurna pembukaan serta penutupan sidang DPRD Pimpinan dan Anggota DPRD mengunakan Pakian Sipil Resmi) dan juga diakui bahwa atas pelanggaran tersebut BKjugalangsungmemberikanperingatanagarhaltersebut 
tidak terulang. BK hanya menegur secara lisan dalam rapat tersebut tanpa melakukan pemeriksaan pelanggaran, menyampaikan pertimbangan hasil pemeriksaan, dan merekomendasikan sanksi berupa teguran lisan dan atau tertulis terhadap Anggota DPRD yang melanggar kode etik DPRD.

Sementara pelanggaran yang lain sebagaimana diuraikan pada latar belakang terkait dengan beberapa anggota DPRD melakukan minum-minuman beralkohol (bir) di gedung DPRD menurut Salah satu anggota BK DPRD yang diwawancarai mengatakan bahwa; kasus ini merupakan pelanggaran berat dan sangat mencoreng kiwibawaan anggota DPRD apalagi sempat ramai dimuat dibeberapa media masa namun menurut narasumber mengatakan dirinya tidak bisa berbuat banyak karena hanya dia sendiri yang meminta agar ini di tindaklanjuti akan tetapi dalam pelaksanaan tidak diproses oleh pimpinan dan anggota-anggota yang lain. Narasumber mengatakan bahwa bagaimana ketua BK memproses Ketua partainya sendiri hal ini bahkan bisa berdampak pada karir politik ketua BK sendiri.

Terkait dengan pelanggaran penipuan dan asusila diakui oleh ketua BK pada saat diwawancara, narasumber mengatakan bahwa masalah ini tidak bisa diproses oleh karena tidak ada pengaduan dari masyarakat ataupun orang yang merasa dirugikan hal inilah yang membuat BK tidak bias memproses terkait dengan pelanggaran tersebut. Selain itu BK juga mengalami kendala-kendala dalam penerapan putusan terkait dengan berbagai persoalan yang ada di DPRD.Berikut ini beberapakendalayangdihadapiBadanKehormatanDPRDKabupaten Kupang dalam menjalankantugasnya;

1. Belum adanya sanksi yang jelas terhadap Pelanggaran Kode Etik berdasarkan peraturan perundang-undangan sehingga Badan Kehormatan belum ada acuan untuk menentukan apakah pelanggaran yang dilakukan anggota DPRD termasuk dalam pelanggaran kategori ringan, sedang atau berat sehingga akan memberikan saksi terhadap anggota DPRD yang melanggar Tata Tertib. Walapun BK sudah memproses dalam memberikan rekomondasi sanksi, tetapi eksekusi pemberian sanksi tetap ada pada pimpinan DPRD, hal ini dapat menimbulkan pro-kontra di antara Badan Kehormatan dan pimpinan DPRD jika terjadi beda pendapat. Apalagi jika yang diadili yaitu sesama partai dari pimpinan DPRD itu sendiri.

2. Independensi Keanggotaan BK DPRD

BK DPRD secara keanggotaan tidaklah independen. Bisa dikatakan BK dilahirkan dengan membawa cacat bawaan. Pasalnya, keanggotaan BK yang dipilih dari anggota DPRD itu sendiri menyulitkan BK untuk menjalankan fungsi pengawasan secara mandiri. Dalam situasi di mana fraksi yang menjadi kepanjangan tangan partai politik membawa misi yang berbeda dengan misi BK, seringkali BK menjadi tidak berdaya. Partai politik beserta elite partai yang masih kental dengan praktik korupsi bukan merupakan lawan sepadan BK. Unsurpolitismenjadihambatanyangsangatmempengaruhi kinerja BK. 
Anggota BK juga merupakan anggota dewan yang terdiri dari masingmasing fraksi yang ada di DPRD. Hal ini sangat berpengaruhpadaBKketikaakanmenegakkankodeetikyangada.Di satusisiBKmerupakanalatkelengkapanyangmemangdibuatuntuk menegakankodeetik,namundi sisilainBKjugamerupakananggota dewan yang berasal dari fraksi-fraksi/Partai politik. Dalam suatu kasus BK sulit menegakan kode etik yang berlaku karena pelanggaran dilakukan oleh ketua Partai dan atau fraksinya sendiri.Hal ini dikerenakan ketika BK hendak menegakan kode etik yang berlaku, namun terbentur oleh posisinya di fraksi tersebut yang dapat terancam karena pelanggar tersebut adalah ketuanya sendiri. Selain itu BK juga sulit bertindak ketika pelanggaran dilakukan oleh teman dekat sendiri yangsesama anggota dewan. Ada sifat saling melindungi diantara sesame anggota Dewan.

Berkaitan dengan hal di atas maka dapat dijelaskan bahwa BK selama ini dikerangkakan oleh tata tertib DPRD yang mengekang. Posisi BK diseting sebagai pengawas internal yang mandul dan pasif karena tiadanya wewenang untuk menjalankan kerja-kerja inisiatif. Dalam tata tertib DPRD, BK baru dapat bekerja jika dua syarat telah dipenuhi, yaitu adanya laporan pengaduan dari masyarakat atas dugaan pelanggaran kode etik anggota DPRD dan jika ada perintah dari pimpinan DPRD. Sepanjang kedua syarat itu tidak dimiliki BK, mereka tidak dapat bertindak apa pun meski pelanggaran kode etik itu sendiri dilihat secara langsung atau diketahui secara langsung oleh anggota BK. Desain BK yang pasif membuat fungsi pencegahan maupun penindakan BK menjadi tidak berjalan sama sekali. Selain itu menurut narasumber sumberdaya dari anggota badan kehormatan itu sendiri perlu dipertimbangkan.

Guna mengatasi kendala-kendala yang dihadapi sebagaimana di sebutkan di atas, upaya-upaya yang ditempuh untuk mengatasi hal tersebut adalah;

1. BK DPRD Kabupaten Kupang ke depan hendaknya melakukan upaya-upaya atau langkah-langkah untuk mengatasi kendala yang terjadi dalam penyelesaian pelanggaran kode etik pada DPRD Kabupaten Kupang antara lain dengan melakukan rapat rutin koordinasi dengan Sekretariat dalam hal absensi kehadiran dewan, peningkatan pengawasan terhadap kinerja anggota DPRD, proaktif terhadap laporan-laporan masyarakat terhadap anggota dewan yang menyimpang dari Tata Tertib dan Kode Etik yang berlaku serta upaya untuk melakukan perubahan tata tertip sehingga kewenangan dari BK semakin lebih besar dalam upaya peningkatan pengawasan terhadap anggota DPRD.

2. Mengidentifikasi tingkat kehadiran anggota DPRD dengan sistim absensi digital hal ini penting agar tidak terjadi kerja sama diantara anggota DPRD terkait absensi kehadiran dalam rapat-rapat maupun kehadiran di lembaga DPRD 
4. Peningkatan sumberdaya anggota Badan Kehormatan dan merekrut staf ahli Badan Kehormatan guna membantu kinerja Badan Kehormatan.

5 Peningkatan peran dan fungsi BK melalui perubahan peratutan tata tertib DPRD Kabupaten Kupang

\section{PENUTUP}

Berdasarkan hasil analisis, maka kesimpulan yang dapat diambil dari penelitian ini adalah sebagai berikut : Pertama, Badan Kehormatan dalam penegakan kode etik belum maksimal dan belum sesuai dengan apa yang diharapkan.Karena pada kenyataannya masih banyak anggota dewan yang melakukan pelanggaran tanpa memandang BK. Kedua, Lemahnya Tata Tertib dan kode etik DPRD. BK hanya bersifat Pasif dan tidak aktif, terbentur Pedoman Tata Beracara BK, masalah prosedural pengaduan yang rumit, kecendrugan anggota BK saling melindungi dan membela sesama anggota DPRD yang melanggar aturan Tata Tertib DPRD, kurangnya dukungan sarana dan prasarana penunjang kinerja anggota Badan Kehormatan dantidak adanya aturan khusus terkait sistim recruitment anggota BK. Saran. Pertama. Untuk ke depan hendaknyaBK dalam melaksananakan tugas dan wewenang selalu berpedoman pada Peraturan Tata Tertib, Kode Etik dan Tata Beracara BK DPRD Kabupaten Kupang yang merupakan domain dari BK. Kedua, Aturanaturan yang ada, yang merupakan domain dari pelaksanaan tugas dan wewenang BK yaitu Tata Tertib, Kode Etik dan Tata Beracara hendaknya lebih dipertegas dengan cara diperbaiki/diubah sedemikian rupa agar anggota BK tidak hanya bersifat pasif tapi sebaliknya anggota BK lebih aktif dalam melakukan tugas dan wewenangnya sebagai pengawal kode Etik DPRD

\section{E. DAFTAR PUSTAKA}

Agus Riwanto, "Strategi Politik Hukum Meningkatkan Kualitas Kinerja DPR RI dalam roduktivitas Legislasi Nasional", Jurnal Cita Hukum, Vol 4, No 2, Edisi September 2016, Jakarta: Fakultas Syariah dan Hukum UIN.

Alfi Martone Singal. "Peran badan kehormatan terhadap pelaksanaan kode etik dalam Meningkatkan pertanggungjawaban DPRD”, Jurnal Cita Hukum, Vol 4, No 3, Edisi Maret 2016, Jakarta, Fakultas Syariah dan Hukum UIN.

Amar VT, 13 November 2016 "Waduh anggota DPRD-kabupaten kupang tipu janda ratusan juta rupiah" tersedia di website http://www.kupangmedia.com/

Arbi Sanit, Perwakilan Publik Indonesia. Rajawali, Jakarta, 1985. 
Bryan Rizky Immanuel Rindengan, " Peranan Sekretariat DPRD Dalam Mendukung Fungsi DPRD (studi di Sekretariat DPRD kota Tomohon)", Jurnal Cita Hukum, Vol 13 No 17 Edisi September 2013, Jakarta: Fakultas Syariah dan Hukum UIN.

Fajar Bayu Susetjo, Untung Dwi Hananto, "Tugas dan Wewenang DPRD dalam Pelaksanaan Pengawasan APBD di Kabupaten Bekasi”, Ejournal, Vol 1, No 2, edisi 2013, Semarang: Fakultas Hukum Universitas Diponegogo.

Ibrahim. Z Fahmy Badoh, "Tugas dan Fungsi Badan Kehormatan DPR”, Jurnal Cita Hukum, Vol 3, No 2 Edisi Juni 2012 Jakarta, Fakultas Syariah dan Hukum UIN.

Joo Boi, 13 Desember 2016 "Anggota DPRD kabupaten kupang sekamar dengan istri orang" tersedia di website http://www.timorexpress.fajar.co.id

Julius Akoit 7 Oktober 2016 ."Pesta Bir di Gedung DPRD kabupaten kupang oleh anggota DPRD". tersedia di website https://www.tribunnews.com.

Mochamad Isnaeni Ramadhan, "Peran BK-DPRD dalam Penegakan Etika", Makalah disampaikan pada Legislatif Confernce International Network for Regional Development, Jakarta tanggal 8-9 Mei 2015

Nur Habibi, "Praktik Pengawasan Etika Dewan Perwakilan Rakyat Republik Indonesia”, Jurnal Cita Hukum, Vol 1 No 1Edisi Juni 2014, Jakarta, Fakultas Syariah dan Hukum UIN.

Soejono Soekanto, 2007 Pengantar Penelitian Hukum, Jakarta, Universitas Indonesia Press

William Franata, "Tugas dan Wewenang Badan Anggaran DPRD Kota Bekasi Dalam Penyusunan Anggaran Pendapatan dan Belanja Daerah (APBD)", Ejournal, Vol 1, No 4, Edisi 2012 , Semarang: Fakultas Hukum Universitas Diponegogo.

Wawancara internal dengan Ketua Badan Kehormatan DPRD kabupaten Kupang tanggal 9 April 2017

Yasin, Muhammad, "Suap dalam Proses Legislasi, Penelusuran Awal" dalam Jurnal Hukum Jentera, Vol 5 No, 3, Edisi Oktober 2005. Jakarta Fakultas Syariah dan Hukum UIN Syarif Hidayatullah. 